\title{
Pendidikan Kesehatan tentang Deteksi Dini Kanker Payudara melalui Pemeriksaan Payudara Sendiri (Sadari)
}

\author{
Julaecha \\ Prodi D III Kebidanan STIKes Baiturrahim Jambi \\ email: echa_mamee@yahoo.com
}

Submitted : 09/12/2020

Accepted: 21/06/2021

Published: 28/06/2021

\begin{abstract}
Breast cancer is one of the leading causes of death and many types of cancer occur in women. The incidence of breast cancer increases with age, however, young age is not a safe guarantee of breast cancer. The high incidence of breast cancer resulted in not a few sufferers of breast cancer that led to death. Signs and symptoms of breast cancer can be found as early as possible, the higher the cure rate. Breast self-examination (BSE) is one effective step if done as early as possible when women reach reproductive age. The purpose of community service is that teenagers consciously want to do breast self-examination routinely every month so as to reduce and reduce the risk of breast cancer. The method used by giving counseling and demonstration about BSE techniques to young women. An indicator of the success of this activity is that young women are able and able to conduct self-examination. Community service is carried out in Sungai Putri, Danau Sipin Subdistrict, Jambi City on December 2018 - January 2019. The results of this activity are all young women understand and understand and can do their own breast examination (BSE).
\end{abstract}

Keywords:breast cancer, breast self-examination, health education, young women

\begin{abstract}
Abstrak
Kanker payudara merupakan salah satu penyebab utama kematian dan jenis kanker yang banyak terjadi pada wanita. Insiden kanker payudara meningkat seiring bertambahnya usia, akan tetapi, usia muda bukan menjadi jaminan aman dari kanker payudara. Tingginya angka kejadian kanker payudara mengakibatkan tidak sedikit penderita kanker payudara yang berujung pada kematian. Tanda dan gejala kanker payudara dapat ditemukan sedini mungkin, maka tingkat kesembuhan semakin tinggi. Pemeriksaan payudara sendiri (SADARI) merupakan salah satu langkah efektif jika dilakukan sedini mungkin ketika wanita mencapai usia reproduksi. Tujuan pengabdian kepada masyarakat ini adalah agar remaja secara sadar mau melakukan pemeriksaan SADARI secara rutin setiap bulan sehingga dapat menurunkan dan mengurangi resiko kanker payudara. Metode yang digunakan dengan memberikan penyuluhan dan demonstrasi tentang tehnik SADARI kepada remaja putri. Indikator keberhasilan dari kegiatan ini adalah remaja putri mampu dan dapat melakukan pemeriksaan SADARI. Pengabdian kepada masyarakat ini dilakukan di kelurahan Sungai Putri, Kecamatan Danau Sipin Kota Jambi pada bulan Desember 2018 s/d Januari 2019. Hasil kegiatan ini seluruh remaja putri mengerti dan memahami serta dapat melakukan cara melakukan pemeriksaan payudara sendiri (SADARI).
\end{abstract}

Kata Kunci: kanker payudara, pemeriksaan sadari, pendidikan kesehatan, remaja putri

\section{PENDAHULUAN}

Kanker payudara merupakan kanker yang paling banyak menyerang perempuan. Setiap 2 dari 10.000 perempuan di dunia diperkirakan akan mengalami kanker payudara setiap tahunnya. Kanker payudara merupakan salah satu penyebab utama kematian yang diakibatkan oleh kanker pada perempuan di seluruh dunia. Menurut data GLOBOCAN (IARC) tahun 2012 diketahui bahwa kanker payudara merupakan penyakit kanker dengan persentase kasus baru tertinggi, yaitu sebesar $43,3 \%$, dan persentase kematian, akibat kanker payudara sebesar 12,9\% (Kemenkes, 2016).

Kanker payudara di Indonesia menduduki peringkat kedua dari semua 
jenis kanker yang sering diderita (Luwia, 2009). Diperkirakan 10 dari 100.000 penduduk terkena kanker payudara dan 70\% dari penderita memeriksakan dirinya pada stadium lanjut (Mulyani 2013)

Kanker adalah penyakit akibat dari pertumbuhan abnormal sel yang tidak terkendali sehingga sel ini terus tumbuh, merusak bentuk dan fungsi organ. Sel ini kemudian menyusup dan menyebar serta merusak jaringan sekitar dan juga menyebar ke organ tubuh yang lain. Kanker payudara adalah kanker yang paling sering pada perempuan dan merupakan penyebab kematian kedua akibat kanker ada wanita, setelah kanker leher rahim.

Faktor penyebab kanker payudara diduga karena peubahan gaya hidup seperti kebiasaan makan makanan cepat saji, seringnya terapar radiasi dari media elektronik dan perubahan kondisi lingkungan (YKPJ 2011). Penyebab lain tingginya angka kejadian kanker payudara ini adalah karena terbatasnya pengetahuan masyarakat tentang kanker payudraa, rasa takut akan operasi, rasa malas dan malu memperlihatkan payudara, dan tidak tahu cara deteksi dini dan cara penanggulangannya (Yayasan Kanker Indonesia 2012)

Kecenderungan peningkatan jumlah penderita kanker payudara, maka perlu dilakukan upaya untuk pencegahannya. Kemenkes RI telah melaksanakan program deteksi dini kanker payudara dengan melakukan pemeriksaan payudara sendiri (SADARI) yang bertujuan untuk mendeteksi dini adanya kanker payudara atau tidak. (Olfa, 2013)

Pemeriksaan payudara sendiri (SADARI) merupakan salah satu langkah deteksi dini untuk mencegah terjadinya kanker payudara yang akan lebih efektif jika dilakukan sedini mungkin ketika wanita mencapai usia reproduksi. Pemeriksaan SADARI dilakukan setiap bulan atau setiap tiga bulan sekali untuk dapat mendeteksi secara dini jika terdapat kelainan dan segera mendapatkan penanganan yang tepat. (Suryaningsih, 2011) Pemeriksaan payudara sendiri) merupakan tehnik yang sederhana dan baik untuk deteksi dini kanker payudara, meskipun SADARI tidak mahal, tidak menimbulkan rasa nyeri, tidak berbahaya dan nyaman, namun hanya sekitar dua pertiga wanita yang mempraktikan sekurang-kurangnya sekali setahun dan hanya sepertiga mempraktikan tiap-tiap bulan, dan wanita yang melakukan dengan benar. Hal ini disebabkan karena minimnya informasi dan kurangnya pengetahuan tentang SADARI. (Tjindarbumi 2008)

Hasil penelitian Ekasiroh (2017) Faktor-Faktor Yang Berhubungan Dengan Perilaku Remaja Putri Tentang Deteksi Dini $\mathrm{Ca}$ Mammae Menggunakan Teknik SADARI di SMK Makarya 1 Jakarta Tahun 2017. Menyatakan ada hubungan pengetahuan dengan perilaku remaja putri tentang deteksi dini $\mathrm{Ca}$ Mammae menggunakan teknik sadari, Ada hubungan motivasi dengan perilaku remaja putri tentang deteksi dini $\mathrm{Ca}$ Mammae menggunakan teknik SADARI, Ada hubungan sumber informasi dengan perilaku remaja putri tentang deteksi dini Ca Mammae menggunakan teknik sadari, dan ada hubungan gaya hidup dengan perilaku remaja putri tentang deteksi dini $\mathrm{Ca}$ Mammae menggunakan teknik SADARI.

Berdasarkan uraian latar belakang diatas, dimana kecenderungan peningkatan jumlah penderita kanker payudara maka perlunya pemberian informasi tentang kanker payudara dan cara melakukan deteksi dini kanker payudara pada remaja putri dengan melakukan pemeriksaan payudara sendiri (SADARI).

\section{TARGET DAN LUARAN}

Sehubungan dengan permasalahan yang dialami oleh mitra, maka analisis tim pengabdian kepada masyarakat dengan mitra yakni ketua RT kelurahan Sungai 
Putri mengadakan kegiatan sebagai berikut": Memberikan pendidikan kesehatan dengan menghadirkan remaja putri dan memberikan informasi dan pengetahuan tentang detesi dini kanker payudara melalui pemeriksaan SADARI, media yang digunakan adalah LCD, leaflet, panthom payudara dan demonsrasi tentang cara pemeriksaan payudara sendiri (SADARI).

Luaran yang diharapkan pada pengabdian kepada masyarakat ini adalah peningkatan pengetahuan remaja putri tentang kanker payudara dan cara deteksi dini kanker payudara melaui pemeriksaan payudara sendiri (SADARI).

\section{METODE PELAKSANAAN}

Pengabdian kepada masyarakat berupa Pelaksanaan kegiatan Penyuluhan tentang deteksi dini kanker payudara melalui pemeriksaan payudara sendiri (SADARI) pada remaja putri di Kelurahan Sungai Putri Kecamatan Danau Sipin, Kota Jambi. Kegiatan ini sebagai implementasi dari tri dharma Perguruan Tinggi. Metode yang digunakan adalah ceramah, diskusi tanya jawab, dan demonstrasi. Metode ceramah digunakan pada saat pemberian informasi deteksi dini kanker payudara melalui pemeriksaan payudara sendiri (SADARI) Metode diskusi untuk mengetahui pemahaman peserta tentang kanker payudara dan cara melakukan tehnik SADARI. Alat dan Media yang digunakan adalah LCD, Laptop, phantoom payudara, slide power point, Pengabdian kepada masyarakat ini dilakukan pada bulan Desember 2018 s/d Januari 2019.

\section{HASIL DAN PEMBAHASAN}

Kegiatan pengabdian kepada masyaakat ini telah dilaksanakan di kelurahan Sungai Putri Kota Jambi, dihadiri oleh remaja putri, Setelah diberikan penyuluhan dan diskusi, kegiatan dilanjutkan dengan demonstrasi pemeriksaan payudara sendiri (SADARI), berdasarkan hasil diskusi dan demonstrasi adanya pemahaman remaja putri tentang deteksi dini kanker payudara melalui pemeriksaan SADARI dditunjukkan dengan peserta dapat menjawab beberapa pertanyaan dan dapat melakukan kembali cara atau step by step melakukan pemeriksaan SADARI.

Hasil pengabdian kepada kepada masyarakat ini sejalan dengan penelitian Utama Ladunni L tahun 2017 tentang pengetahuan remaja putri tentang pemeriksaan payudara sendiri (SADARI) di Lampung menunjukkan bahwa terdapat hubungan yang bermakna antara pengetahuan tentang pemeriksaan SADARI dengan perilaku SADARI. (Utama Ladunnni L, 2017). Untuk menemukan gejala awal kanker payudara dapat dideteksi sendiri oleh kaum wanita, jadi tidak perlu seorang ahli untuk menemukan awal kanker payudara.

Kanker payudara merupakan penyebab utama kematian diantara semua penyakit kanker yang dialami wanita di Indonesia salah satunya karena terdeteksi pada stadium lanjut. Salah satu faktor keterlambatan diagnosis pada kanker payudara karena keengganan wanita untuk melakukan deteksi dini kanker payudara. Kengganan melakukan pemeriksaan dini dengan alasan melakukan pola hidup sehat, tidak ada keluarga yang memiliki penyakit kanker payudara, merasa cukup sibuk bahkan lupa. (Daliana et al, 2014)

Di dukung oleh penelitian Ambarwati, 2014. Tentang Hubungan pengetahuan SADARI dengan minat Deteksi dini Kanker Payudara. Pada Remaja Putri di SMAN 1 Karang Klaten berdasarkan penelitiannya didapatkan bahwa tingkat pengetahuan terbanyak berada pada katagori sedang $73,4 \%$ sedangkan tingkat pengetahuan terendah berada pada katagori buruk 11,1\% . Rendahnya tingkat pengetahuan masyarakat mengenai pentingnya pemeriksaan SADARI disebabkan oleh kurangnya 
informasi serta tingkat kewaspadaan masyarakat terhadap kanker payudara. (Ambarwati, 2014)

Pengetahuan adalah kesan dalam pikiran manusia sebagai hasil penggunaan panca indranya dan segala sesuatu apa yang diketahui bedasarkan pengalaman yang didapatkan oleh setiap manusia. Seseorang yang memiliki pengetahuan yang tinggi dalam sesuatu hal, akan mudah menerima perilaku yang lebih baik. Tingginya pengetahuan akan berdampak terhadap proses perubahan perilaku yang akan dilakukan sehubungan dengan permasalahan yang dihadapi. ( Notoatmodjo, 2010)

Tingginya pengetahuan akan berdampak terhadap proses perubahan perilaku yang akan dilakukan sehubungan dengan permasalahan yang dihadapinya. Banyak perempuan yang tidak melakukan pemeriksaan payudara sendiri secara rutin setiap bulan kemungkinan dikarenakan minimnya pengalaman responden terhadap paparan kasus kanker payudara seperti tidak ada anggota keluarga yang mengalami kanker payudara, kerabat atau orang lain yang pernah responden lihat, pengalaman tersebut membentuk perasaan simpati, kecemasan maupun ketakutan sehingga menginduksi perilaku melakukan pemeriksaan payudara sendiri.

Penyuluhan tentang deteksi dini kanker payudara sebagai bagian dari promosi kesehatan sebagai upaya untuk meningkatakan kesehatan. Pemeriksaan SADARI sebaiknya dilakukan secara berkala setiap bulan agar benjolan dapat ditemukan pada stadium dini dan dapat dilakukan tindakan yang tepat apabila ditemukan benjolan maupun keluhan lainnya pada payudara (Maulana, 2013)

Saat yang paling tepat melakukan pemeriksaan Payudara sendiri (SADARI) adalah hari ke 5-7 setelah menstruasi, dimana payudara tidak mengeras, membesar atau nyeri lagi, unguk wanita yang menopause dapat melakukan pemeriksaan kapanpun dan disarankan dilakukan pada setiap awal atau akhir bulan.

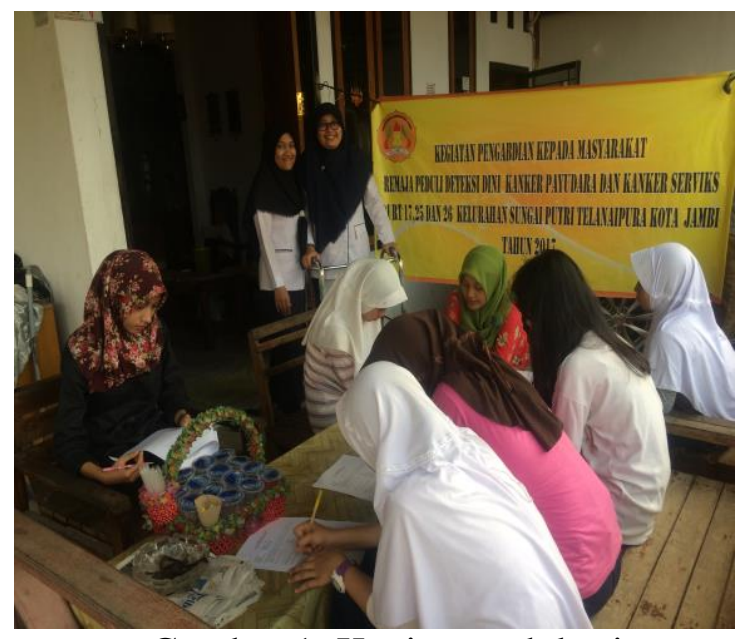

Gambar 1. Kegiatan edukasi

\section{KESIMPULAN DAN SARAN}

\section{Kesimpulan}

Berdasarkan hasil dari pengabdian kepada masyarakat ini adalah remaja putri memahami dan dapat melakukan pemeriksaan SADARI, serta mengetahui waktu yang tepat kapan melakukan pemeriksaan Payudara sendiri (SADARI), cara yang efektif untuk deteksi dini kanker payudara, murah dan mudah dilakukan mungkin. Remaja putri mengenal struktur payudara normalnya, oleh karena itu jika ada benjolan atau ada hal yang tidak normal lainnya, maka mereka akan langsung menyadari.

\section{Saran}

Remaja purtri Diharapkan mencari dan melakukan pemeriksaan SADARI secara rutin setiap bulan untuk mengetahui ada tidaknya gejala penyakit kanker payudara pada dirinya sehingga apabila ada kelainan dapat di deteksi secara dini.

\section{UCAPAN TERIMAKASIH}

Terima kasih kepada Bapak Ketua Sekolah Tinggi Ilmu Kesehatan Baiturrahim Jambi yang telah memberikan dana dan Bapak ketua RT 17, 26, 25 kelurahan Sungai Putri Kota Jambi yang 
telah memberikan izin dan memfasilitasi kegiatan pengabdian masyarakat ini.

\section{DAFTAR PUSTAKA}

Ambarwati, T Sugita S, dan Susilowati, D 2014. Hubungan pengetahuan SADARI dengan Minat Deteksi Dini Kanker Payudara Pada Remaja Puteri Kelas XI di SMAN 1 Karangdowo Klaten. Jurnal Kebidanan Indonesia. http://jurnal.akbid-

mu.ac.id/index.php/jurnalmus/article/ view/43

Daliana N, Farid, N. Aziz N, Al-Sadat N, Jamaludin M, Dan Dahlui, M. (2014) Clinical Breast Examination As The Recommended Breas Cancer Screening Modality in a Rural Community in Malysia. What are the factors that Could Enhance its Uptake? Plos One 9 (9), 1-7. http://doi.org/101371/journal.pone.01 06469

Kemenkes RI 2010 Kepmenkes RI nomor 796/ menkes/SK/SK/VII/2010 tentang pedoman Kanker Leher Rahim. Jakarta. Kemenkes RI

Kemenkes R1 2015 Panduan Program Nasional Gerakan Pencegahan dan Deteksi Dini kanker leher Rahim dan kanker Payudara. Direktorat Jendral Pengendalian Penyakit dan Penyehatan Lingkungan. Direktorat Pengendalian Penyakit Tidak Menular

Kemenkes RI 2014 Direktorat Jendral Pengendalian Penyakit dan Penyehatan Lingkungan, Direktorat Pengendalian Penyait Tidak menular

Luwia, M.S 2009. Problematika dan Perawatan Payudara. Jakarta PT. Kawan Pustaka

Mulyani (2013) kanker payudara dan PMS pada kehamilan Ypgyakarta, Nuha Medika

Notoatmodjo S. 2010. Ilmu Perilaku Kesehatan. Jakarta, Rineka Cipta. 2040
Olfa, Yustiana (2013) Kanker Payudara dan SADARI, Jakarta: Nuha Medika

Suryaningsih dan Bertiani (2009) Kupas Tuntas Kanker Payudara. Yogyakarta. Paradigma Indonesia

Tjindarbumi, 2008. Penemuan Dini Kanker Payudara dan Penanggulangannya

Yayasan Kanker Indonesia (2012) Kanker

Payudara. dalam Diagnosa Dini kanker Keganasan Serta

Penanggulangannya, Jakarta. FKUI 2008

Utama Ladunni Lubis, Pengetahuan Remaja Putri Tentang Pemeriksaan Payudara Sendiri (SADARI) dengan Perilaku SADARI, Jurnal Ilmu Kesehatan 2 (1) $2017,81-86$ 